\title{
Folly, Mental Health, Disembodiment
}

\author{
Seonaid Abernethy \\ LL.M Hons Auckland, Barrister Sole, Auckland, New Zealand
}

Copyright $\bigcirc 2017$ by authors, all rights reserved. Authors agree that this article remains permanently open access under the terms of the Creative Commons Attribution License 4.0 International License

\begin{abstract}
Maori World-View (a pre-industrial cultures' episteme of an individual intricate relationships to Nature and others) exemplifies Aristotles Good and the concept of embodied proportionality. Maori World-View is a window through which to understand embodiment, proportionality and The Good otherwise obscured by Cartesian and Ramist methodology. In modern 'Mental Health' practice of risk assessment, there has been a disembodiment, a disproportionality and loss of the end of the Good. This loss is best approached through the historicity of Shakespeares' Twelfth Night for varied reasons. Twelfth Night shows us that an embodied personal performance within a distemperature (mild 'mental health' illness) requires a critical distance from technology and retrieval of proportionality, individuated in any pre-industrial culture.
\end{abstract}

Keywords Mental Health, Disembodiment of Risk, Maori World View, Twelfth Night, Critical Distance from Technology

\section{Introduction}

Tena koutou katoa

Greetings everyone

Ko Tauhara te maunga

The Mountain (person) of Tauhara is the mountain I identify with

Ko Taupo nui-a-tia te roto

The Lake (person) of Taupo Nui-a-Tia is the lake I identify with

Ko Waikato te awa

The River (person) of Waikato is the river I identify with

Ko Ngati Paheka te iwi

The tribe that I relate to is the Pakeha tribe

No Taupo nui-a-tia ahau

I came from Taupo

Kei Maungawha taku kainga inaianei

\section{Now my home is by the Mountain of the Whau tree}

Ko Seonaid Abernethy taku ingoa

My name is Seonaid Abernethy

This common Māori language oral greeting [1] at any planned gathering, identifies a person by his or her relation to personified nature. It shows a personal relationship between me and my local mountain, lake and river within the particular time and space of my growing up. This is the Good for me. It demonstrates the place where I fit [2]. It is a hermeneutics for my sense of self and experience.

This is a relatedness of mind, soul and body to a particular Nature ( from which a subsistence livelihood sprang) and to the people of an individual's own locality [3]. It exemplifies Aristotle's 'the Good,' which was the foundation for proportionality in Aristotle's livelihood and justice [4].

When I identify myself in the traditional Māori greeting, I indicate what is the Good for me, and in this, is the sense of Aristotle's proportionality. This epistemological relatedness in Māori World-View [5] is Aristotle's Good.

\section{The Good and Proportionality}

The writer follows Ivan Illich in outlining what is proportionality in a pre-industrial culture (errors and omissions excepted). A proportional world (common to Mediterranean, Far Eastern, Mexican, Aztec and Mayan cultures) assumes a correspondence between heaven and earth. It is a mutually constitutive complementarity between a here and a there. This complementarity corresponds in some way to a will that is good [4].

"The Good... is what is uniquely and incomparably appropriate in a given setting. It observes a certain scale, displays a certain proportion. It fits and the senses can recognise this fit, just as they can recognise what is out of tune [5].

Illich outlines the loss of the sense of what is fitting and virtuous behaviour within the end of the Good. He states that the sense of fit has been replaced by "values" which rank things according to a mathematical or economic scale, such criteria arising since the Enlightenment and propagated by the rise of the global industrial marketplace based on a 
money exchange [6].

The personal relationship with Nature and others in Maori world-view is a living, current example of the Good in Aristotle and Illich. In this, we have a sense of embodiment which is not a set of psychological attributes [7] but a bodily felt sense of home, time and space which is local and personal. When we lose the sense of the Good and replace it with "values," we lose proportionality.

\section{Loss of Proportionality}

There is a disembodiment and consequent loss of proportionality in folly which is now something called 'mental health'. The term 'folly' in Middle English emanated from the French 'folie,' or madness. It meant foolishness or lack of good sense [8]. It is a definition related to the body. 'Foolishness' has been transformed into a medical key word, 'mental health', emanating from a clinical, technological, gaze. There is a loss of a sense of the felt body. There has been an epistemological shift from a felt sense of the body in relation to others in folly - to the diagnostic, medical gaze of service professionals. I approach this shift or loss through Shakespeare's Twelfth Night for the reasons which follow.

\section{Distemperature as Madness in Twelfth Night - the Beginning of Confinement for Madness}

The Renaissance distinguished between "being out of one's wits" as not able to know what one did or said or what others did or said to them (this situation where the person was not responsible for their actions) and madness being melancholy or a distemperature [9]. Twelfth Night is about the latter type of "distemperature". Shakespeare uses words such as "mad" and "madness" more often in Twelfth Night than in any other of his plays [10].

Shakespeare's Twelfth Night demonstrates "distemperature" as a tolerable folly. At the same time, Shakespeare identifies the new treatment for madness in the $16^{\text {th }}$ century - when reason began to exclude 'unreason' by way of confinement rather than exile [11]. The delusions and "impossible passages of grossness" [12] of Malvolio in Shakespeare's Twelfth Night are assessed, and treated in detention, by persons with whom Malvolio was in an embodied relationship. It has to be assumed that the community of Twelfth Night and its relationships are the Good for these characters.

While our own Māori language and culture surround those of us who inhabit New Zealand (Aotearoa) with a profound sense of relatedness and embodiment, repeated orally and politically around the country in various ways every day, the writer has no learning as to how Maori customarily treat folly as a 'distemperature'.

Instead, recourse to Shakespeare's Twelfth Night (first performed 1601) exposes a historical perspective on Western mental health. Twelfth Night dramatizes personal performance in madness within a context of a boom in body awareness [13] almost contemporaneous with the Cartesian moment which led to the mind/body split so visible in disembodied legal reasoning [14]. That is to say, characters express desire and feelings poetically, in a context of classical learning and renaissance. There are poetic devices such as the Petrarchan (body) blazon [15] and the Ovidean transformative effect of desire on the body [16].

\section{Personal Performance of Distemperature in Twelfth Night}

"If this were played upon a stage now, I could condemn it as an improbable fiction."

- Fabian in Twelfth Night, Act III Scene IV

In Twelfth Night, twins Viola and Sebastian are separated by a storm at sea. Each believes the other drowned. They are reunited in the twelve days of foolery and allowed misrule after Christmas - the eve of the Epiphany [17]. This period of festive drunkenness and disorder provides a background of mistaken identity, gender transformation, unrequited passion, class mobility and a dark undercurrent of dour Lenten materialism [18].

Briefly, Viola washes ashore in Illyria, on the coast of the Mediterranean and disguises herself as Cesario, a servant to Count Orsino. Orsino sends Viola/Cesario to woo Lady Olivia on his behalf.

Parallel to this suit, is the marriage fantasy of Malvolio, Lady Olivias steward. Malvolio, is a "kind of Puritan" disapproving foolery and drunken revels but socially ambitious. He imagines he might be Olivia's husband, and could be elevated to Count. In a scene prior to any trick, Malvolio wanders around, talking to himself, gesticulating at nothing and pretending he is Count with power over Olivia's cousin Sir Toby [19].

Sir Toby and others in the household, incensed at Malvolio's repressive, dry, self-important sermonising, plan a trick on him. Malvolio finds a letter ostensibly from Olivia to him. He is directed to woo Olivia by actions that Olivia detests. Malvolio appears outlandishly dressed and behaving with amazing arrogance, grandiosity and delusions. Shocked, Olivia tells Sir Toby to look after him.

Sir Toby and others, pretend that Malvolio is possessed by the Devil and mad. They lock him in a dark prison. Malvolio is subjected to a barrage of circular reasoning imposed on him to demonstrate his madness. After this humiliation, Malvolio is released, and his marital ambitions further publically exposed as comical delusions. However, Malvolio's personal performance of endurance through all this appears to restore him to reality.

The religious, historical and social context of Twelfth Night imbues it with significance for "mental health" today. Erasmus' satire on excesses in the Catholic Church ('In 
Praise of Folly' 1509) personified madness in the mythological Follies. The Protestant Reformation marked a shift from madness seen as a sign of cosmic unease external to man. Madness insinuated itself inside man by way of visualisation of man's self-love, weakness, dreams, illusions [20] and that is, exactly how Malvolios' distemperature is presented. Shakespeare's Malvolio is shown as sick with self-love and this was a kind of madness [21].

\section{The Disembodiment of the Clinical Gaze}

Today, Malvolio might undergo an assessment, detention and treatment but in a different context and from a different source.

$\mathrm{He}$ is assessed, detained and treated by way of a medical diagnosis of service professionals who act according to a rule of law. The compulsory detention, assessment and treatment under the New Zealand Mental Health (Compulsory Assessment and Treatment) Act 1992 (The Mental Health Act) is carried out under a diagnosis and a risk assessment / management process. The legal and medical risk component of this lies in the second limb of the definition of mental disorder - that the diagnosis as defined poses a serious danger to the health or safety of self or others or seriously diminishes the capacity of the person to take care of themselves. Criteria of danger to others also exists ordinarily in US States [22].

\section{Diagnosis and Risk}

There are now 280 different mental disorders under the U.S. Diagnostic and Statistical Manual of Mental Disorders (DSM-IV) $4^{\text {th }}$ edition which is listed on the website of the New Zealand Ministry of Health [23].

The DSM-V includes hoarding as a disorder [24]. In 2014, an Australian newspaper celebrated the fact that the famous painter Margaret Olley had died before this hoarding diagnosis came out. They said that otherwise she may have been boxed into a "treatable diagnosis" instead of respecting her as the inspiration and National Treasure that she was [25]. Her house contained 22,000 items including a dead rat which she had ignored while devoting herself to following the sunlight around the house, in order to paint still life in different lights of the day. It was joked of the clutter of her house that it was an archaeological site and that, if you dug deep enough, there would be layers that could be carbon dated!

During 2013, approximately 10,270 people in Aotearoa /New Zealand came into contact with the Mental Health Act. On average 6,340 people were subject to either compulsory assessment or compulsory treatment on a given day [26].

It is the statutory and case law definition which imposes on clinicians and lawyers, a risk assessment and/ or management. An example of this in practice is a law case which formulises how to judge whether a person is a serious danger to themselves or others. Re Mental Health (Serious Danger) [2012] NZFLR 1 expresses the formula as follows; (i) what is the magnitude or gravity of the behaviour concerned? (ii) What is the likelihood of the behaviour occurring? (iii) What was the proximity or imminence of the behaviour, in other words, how soon or quickly might it occur? (iv) What is the frequency of the behaviour, that is to say how often might it occur?

This requires a risk assessment or management plan from clinicians. There is however, a critique of risk, emanating from academics, and the very practitioners who are forced to use it. Because it is algorithmic, risk is opposed to the felt body.

\section{Risk and the Felt Body}

There is "a shift from the analysis of an individual patient as an individual to be understood as such, to a calculus that is based on collecting items of information (now redefined as risk factors). The focus on discrete, specifiable and measurable risk factors more common in those who are violent than those who are not, moves us away from an attempt to understand the individual patient as an agent with intentions, feelings, desires, preferences, specific needs and so on. Instead the individual is placed within a category according to how high the score on an algorithm of factors statistically related to the probability of committing a violent act. The result may be an attenuation of focus on the individual as a living person acting in relation to the situations that he or she is living in and giving meaning to [27].

It is said that risk has become a religious ideology and that it is "an invitation to intensive self-algorithmization, not only disembodying but reducing myself entirely to misplaced concreteness by projecting myself on a curve" [28].

There is a large body of research indicating that risk assessment is not a reliable tool to predict self-harm or harm to others [29]. Risk assessment is "science fiction" [30], or a highly risk-averse culture sees serious violent incidents as a failure of expertise by someone or an institution who is culpable or accountable [31]. However, professionals are asked for the impossible - namely to predict and prevent episodes of serious violence [32].

Paradoxically, there is always a face to face meeting between a patient (and family) and the professionals clinicians, lawyer, Judge. Distemperature and medicine are mediated to finality by the bodily meeting in a modest room or on a Maori whare nui watched over by a Maori Guardian. In this final outcome of whether or not the patient will be subject to a Compulsory Treatment Order, the patient and family can speak. As a practising mental health lawyer, it is here that I have heard the most eloquent and moving expressions of humility from patients. Despite the drugs and illness, the human spirit sometimes breaks out in a burst of authenticity. 


\section{Conclusions}

Risk assessment of distemperature, is a non-somatic act tied onto the end of a clinical diagnosis of a bodily condition. It aims at safety and certainty.

Mental health technology may be desirable for those who are out of their wits and a danger to others, but in determining this, there is a necessity to maintain a critical distance from technology. In finding distemperature, a proportionality has to be sought between the felt body and engineered instrumentalities in mental health [33]. In our own Māori language and culture there is a practice of personal performance in relatedness and embodiment that has only 175 years of colonised repression and survives with remarkable warmth. It remains the proportionate Good for us, practised in the interstices of mental health.

\section{REFERENCES}

[1] It is common because a mandatory opening in any cultural/political event. Eg see Prime Minister Bill English's address in fluent Maori language to Ratana Pa gathering on 28 January 2017 accessible at

http://www.nzherald.co.nz/nz/news/article.cfm?c_id=1\&obje ctid=11787113 Supermarkets, libraries, courts, government offices carry bilingual headings now.

[2] Discussion with Dr. Valance Smith, Lecturer, Te Ara Poutama, AUT University, 24/8/15. "This pepeha or personal statement connects the person to their sense of 'home'. It is an assertion of one's mana to their land, a reference to geographical landmarks like mountains, rivers and lakes that serve as cultural markers of belonging to a place." Each mountain, river, lake, sea is referred to with the personal pronoun 'ko'. This is echoed in the French personalist movement of Ellul and Charbonneau." See also C. Roy. Ecological Personalism: The Bordeaux School of Bernard Charbonneau and Jacques Ellul, Paper for a conference, 'Prophet in the Wilderness: A Centenary Celebration and Critical Review of Jacques Ellul (1912-1994),' Wheaton College, July 8-10, 2012.

[3] R. Joseph. Legal Challenges at the Interface of Māori Custom and State Regulatory Systems: Wahi Tapu, Yearbook of New Zealand Jurisprudence Vol.13, No.14, 2012, 160-193. See also: Linda Te Aho. Indigenous Challenges to Enhance Freshwater Governance and Management in Aotearoa New Zealand - The Waikato River Settlement, The Journal of Water Law Vol.20, No.5, 2010: 285.

[4] D.A. Rees Ed. Aristotle, The Nicomachean Ethics. a commentary by H.H. Joachim. OUP London 1951. "The good for man turns out to be activity of the soul in accordance with virtue". P 51. See also C. Warne Aristotle's Nicomachean Ethics. Continuum London 2006. "Eudaimonia is an activity of the part of the soul that has reason in accordance with virtue throughout a whole life". P 36. See also G. Dalton, ed. Primitive Archaic and Modern Economies, Essays of Karl Polyani, Beacon Press, Boston, 1968. Chapter 5: 'Aristotle Discovers the Economy' 81-82; Introduction at xix. See also C. Hann and K. Hart, eds. Market and Society: The Great Transformation today, Cambridge University Press,
Cambridge, 2009, 3. See also E. Engle. 'The General Principle of Proportionality and Aristotle,' Aristotle and the Philosophy of Law Theory Practice and Justice. L. Huppes-Cluysener and N. Coelho, eds. Ius Gentium: Comparative Perspectives on Law and Justice 23, Springer Science and Business Media Dordrecht, 2013: 265. See also B. Schlink, Proportionality (1) 'The Oxford Handbook of Comparative Constitutional Law, eds M. Rosenfeld and A. Sajo, eds. Oxford University Press, Oxford, 2014 viewed 28 August 2014 at www.oxfordhandbooks.com. The proportionality standard is also visible in criminal sentencing: see The Sentencing Act 2002 (NZ) ss, 7 (1) C (d), 8(c) (d), 10, 12 (1), 24A, 107, where proportionality is either specifically mentioned or there is an emphasis on reparation and restorative justice.

[5] D. Naugle. Worldview, Michigan Wm. B. Erdmans Publishing Co. 2002. Worldview "has become one of the central intellectual conceptions in contemporary thought and culture." P 66. A worldview may function socially 'in the shaping of the self and in the fundamental categories of human experience." P 185

[6] Ibid., 132-136.

[7] D. Cayley. The Rivers North of the Future: The Testament of Ivan Illich, Toronto, House of Anansi, 2005: 25.

[8] Ibid., 62-63.

[9] Merleau-Ponty is named by Anna Grear as an important thinker to identify the body as a source of perception and to be included in philosophy. See A. Grear, Redirecting Human Rights Facing the Challenge of Corporate Legal Humanity, Palgrave Macmillan, Hampshire, 2010. See also C. Schilling, The Body in Culture Technology and Society, Sage Publications, London 2005, 1-23.

[10] Oxford English Dictionary.

[11] W. Schleiner, 'The Feste-Malvolio Scene in Twelfth Night against the Background of Renaissance Ideas about Madness and Possession' Aufsatze/Jarrbuch/Deutsche Shakespeare Gellesllschaft West- 1990/Periodical 48-58, 49. See also M. Foucault. Madness and Civilization. Routledge $2001 \mathrm{Tr}$ Howard. Ch 2 'The Great Confinement' 35, 40.

[12] Joost Daalder 'Perspectives of Madness in Twelfth Night', English Studies 1997, Vol. 2, 105-110, 105.

[13] M. Foucault, Madness and Civilization, Routledge, London, 2001, Tr, Howard, Ch 2 'The Great Confinement' 35, 40. The Cartesian moment was still 36 years away when Twelfth Night was first performed in 1601 .

[14] W. Shakespeare, Twelfth Night, Act 3, Sc II, line 45.

[15] A. Findlay and L. Oakley-Brown Eds, Twelfth Night. A Critical Reader Bloomsbury, London, 2014, 2-5: "From somatic to phenomenological debates, it seems that study of Twelfth Night is now synonymous with the body boom... the early modern body boom has run parallel with the analogous foregrounding of body discourse not only in critical domains such as cultural studies and post-modernist theory but also in popular culture Twelfth Night holds gender and embodiment up for scrutiny."

[16] A. Grear. Redirecting Human Rights Facing the challenge of Corporate Legal Humanity, Basingstoke, Hampshire UK Palgrave Macmillan, Hampshire, 2010, 41: "Law (including 
human rights law) is typically conceived of in West as a discourse of reason and Western reason is conceived of as being disembodied to such a degree that the very structure of rationality itself is regarded as transcending structures of bodily experience".

[17] S. Massai, ed. William Shakespeare's Twelfth Night: A sourcebook, Routledge, Milton Park, 2007, 33.

[18] Ibid., 12.

[19] T. Stern, 'New Directions: Inverted Commas around the 'Fun': Music in Twelfth Night,' in A. Findlay and L, Oakley-Brown, eds. Twelfth Night: A Critical Reader, Bloomsbury, London, 2014, 166 - 188, 166.

[20] C. Malcolmson. 'What You Will: Social Mobility and Gender in Twelfth Night' in R.S White ed. Twelfth Night: Contemporary Critical Essays, Macmillan Press, Basingstoke Hampshire, 1996, 160-193, 163, 168. See also M. Bristol. 'Carnival and Theater: Plebeian Culture and the Structure of Authority in Renaissance England' in S. Massia ed. William Shakespeare's Twelfth Night, Oxfordshire, 2007) 70 - 73.

[21] Twelfth Night, Act II Sc V.

[22] M. Foucault, Op Cit, 23. See also R. Schopp 'Mental Health Courts: Competence, Responsibility, and Proportionality ', in R. L. Wiener, E. M. Branks Eds . Problem Solving Courts New York Springer 2013, Ch 10, 164

[23] See note 13

[24] SS 2, 7A - 29. Mental Health (Compulsory Assessment and Treatment) Act, 1992.

[25] DSM-IV Code Table, accessible at http://www.health.govt.nz/nz-health-statistics/data-reference s/code-tables/dsm-iv-code-table, viewed 26/8/15.

[26] Hoarding disorder is defined as the acquisition of and failure to discard possessions that are of limited value leading to clutter and rendering rooms non-functional while compromising safety and hygiene. Seehttps://en.wikipedia.org/wiki/Compu lsive_hoarding.

[27] 'Margaret Olley Art Centre A Boon for the Gold Coast,' accessible http://blankgc.com.au/margaret-olley-art-centre-a-boon-for-t he-gold-coast/

[28] Office of the Director of Mental Health Annual Report 2013, Wellington, New Zealand, Ministry of Health 2014, 19.

[29] G. Szmukler, N. Rose. 'Risk Assessment in Mental Health Care: Values and Costs,' Behavioural Sciences and the Law Vol. 3, 125-140 and 132-133.

[30] D. Cayley. The Rivers North of the Future: The Testament of Ivan Illich, Toronto, House of Anansi, 2005: 210.

[31] T. Wand. 'Investigating the Evidence for the Effectiveness of Risk Assessment in Mental Health Care', Issues in Mental Health Nursing, Vol. 33: 2-7, 2012. See also G. Mellsop, F. Clapham-Howard, J. Turbott, 'Predicting the past or risk management,' New Zealand Medical Journal Vol. 122, No. $1300,2009,60-63$.
[32] G. Szmukler and N. Rose. 'Risk Assessment in Mental Health Care: Values and Costs', Behavioural Sciences and the Law Vol. 31: 125-140, 131-132, 137.

[33] Large, M. 'The relevance of the early history of probability theory to current risk assessment practices in mental health care. 'History of Psychiatry Vol. 24 No. 4, 427-44, 434, 436. "A clinician has to make a choice as to whether losses resulting from violence or self-harm should be the focus. Self-harm and violence do not have the same risk factors... Currently actuarial risk assessment is unable at present to assess the possibility of more than one type of harm or to consider the various risk factors associated with the varying levels of self-harm and harm to others." "A watch can be accurate; a risk assessment for a future act of violence by an individual cannot be." (437) "Stranger homicides by patients with schizophrenia ... are so rare that they are all but impossible to research." (437).

[34] G. Szmukler and N. Rose. Risk Assessment in Mental Health Care: Values and Costs, Behavioural Sciences and the Law Vol. 31: 125-140, 131-132, 137: "It is sometimes forgotten that a violence risk assessment is based on a probabilistic notion and is not really about the prediction of particular violent acts by individual patients. It is, rather, about estimating the incidence of violence in low and high risk groups... Further, while the strength of an association or effect size is at the centre of risk assessment and probability theory, prediction of the occurrence, type, place, timing of violence is quite literally the stuff of science fiction. In reality, no violence risk assessment can determine what a person will do or where or when the violence will occur. "There is a seductive quality to risk assessment: it appears to bring the future into the present and make it calculable. In psychiatry, and in many other areas, the language of risk has replaced that of dangerousness. ... Risk assessment in psychiatry, largely because of decision required by the legal system ... retains its search for those who are inherently high risk or who present a risk above a certain threshold. "Calculability brings a certain sense of objectivity and science to the practices of experts. Calculability seems to act to discipline uncertainty and thus to bring it under our control. It also leads to the idea that actions can and should be taken today to prevent adverse events from occurring in the future. Once a potential event has been transformed into a calculable risk and that risk has been calculated and noted in the records, it must be managed by someone; not to do so become seen as negligent. "Calculability and the apparent ability to bring the future into the present and the moral outrage associated with cause ... mean that serious violent incidents especially homicides by patients can come to be seen as representing a failure of expertise by someone (or an institution) who is accountable and probably culpable. "Risk is a complex, socially constructed and moralized notion. Mental health professionals work within a culture that appears highly risk averse. This at least is the message from the mass media, and the imperative that drives many of our authorities... But those professionals are asked to do what is impossible - to accurately predict and subsequently to prevent rare episodes of serious violence.

[35] S. Samerski. Tools for Degrowth? Ivan Illichs Critique of technology revisited, Journal of Cleaner Production Octoebr 2016 accessible at http://www.sciencedirect.com/science/arti cle/pii/S0959652616316377 